\title{
High Temperatures during Flowering Reduce Fruit Set in Rabbiteye Blueberry
}

\author{
Qin Yang ${ }^{1}$ and Er Liu \\ College of Life and Health Science, Kaili University, Kaili, Guizhou 556000, China
}

\begin{abstract}
Yan Fu
Department of Biology and Environment, Qiandongnan Vocational and Technical College, Kaili, Guizhou 556000, China
\end{abstract}

Fuqiang Yuan, Tingting Zhang, and Shu Peng
College of Life and Health Science, Kaili University, Kaili, Guizhou 556000, China

\begin{abstract}
AdDitional INDEX wORDs. critical temperature, ovule longevity, pollen germination, pollen tube growth, temperature stress, Vaccinium ashei

Abstract. After nearly a decade of development, the scale of blueberry (Vaccinium sp.) cultivation has increased, particularly in south China; however, this region is becoming increasingly challenged by temperature changes during the flowering phenophase. Understanding the effects of temperature on pollen germination and pollen tube growth in blueberry is thus important. Using the rabbiteye blueberry ( $V$. ashei) 'Brightwell', different temperature treatments were carried out during open pollination and cross-pollination with the pollen from rabbiteye blueberry 'Gardenblue' in field, greenhouse, and controlled temperature experiments over two consecutive years. The differences in pollen germination, pollen tube dynamics, and ovule viability following different treatments were analyzed, and the critical temperatures were calculated using quadratic and modified bilinear equations to quantify the developmental responses to temperature. The results showed that the fruit set of the artificially pollinated plants inside the greenhouse was significantly higher than that outside the greenhouse. Furthermore, pollen germination and pollen tube growth gradually accelerated under the appropriate high-temperature range, resulting in reduced pollen tube travel time to the ovule. However, the percentage of the style traversed by the pollen tube did not increase at temperatures greater than $30^{\circ} \mathrm{C}$, and a high-temperature range could accelerate ovule degeneration. Therefore, impairment of pollen tube growth in the upper half of the style following pollen germination and ovule degeneration constituted important factors leading to reduced fruit setting under short periods of high temperature during the flowering phenophase in rabbiteye blueberry. This work advances our understanding of the effect of temperature on pollen germination, pollen tube growth, ovule longevity, and fruit setting in rabbiteye blueberry, and provides a foundation for continued cultivation and breeding enhancement. The findings propose that the tolerance of rabbiteye blueberry to a certain high-temperature range in the flowering phenophase should inform breeding strategies for temperature resistance and that temperature range is also an important indicator of suitable environments for cultivation to mitigate potential temperature stress.
\end{abstract}

Blueberry is a perennial evergreen or deciduous shrub that is native to North America (Wang et al., 2017). Northern highbush blueberry (Vaccinium corymbosum), rabbiteye blueberry, and southern highbush blueberry ( $V$. corymbosum interspecific hybrids) are the three most commercially important species cultivated (Yu et al., 2016). As not all of these species are self-compatible, the need for cross-pollination between botanical varieties is widely acknowledged by commercial growers (Miller et al., 2011; Müller et al., 2013), and pollination by bees is required to improve yield and quality (Nicholson and Ricketts, 2019).

Blueberry is known to contain appreciable levels of phenolic compounds, which have high biological activity and may provide health benefits as dietary antioxidants (Castagnini

Received for publication 25 Jan. 2019. Accepted for publication 1 July 2019. This work was supported by the Technology Cooperation Program of the Guizhou Science and Technology Department, China (No. QIAN KE HE HL ZI [2016]7331), and Key Support Discipline Foundation of Educational Commission of Guizhou Province of China (No. QIAN XUE WEI HE ZI ZDXK [2014] 28). We thank LetPub (http://www.letpub.com) for its linguistic assistance during the preparation of this manuscript.

${ }^{1}$ Corresponding author. E-mail: yangqin1028518@126.com. et al., 2015; Lin et al., 2016; Shen et al., 2014). Blueberries are a rich source of flavonoids, phenolic acids, anthocyanins, stilbenes, and tannins, as well as nutritive compounds such as sugars, essential oils, carotenoids, vitamins, and minerals (Nile and Park, 2014). In addition, there has been a growing trend in the use of blueberry extracts as ingredients in functional foods and dietary supplements (Dróżdż et al., 2018). Blueberry fruit have thus become increasingly popular because of their high nutritional value and desirable flavor (Chu et al., 2017).

After nearly a decade of development, China recently became one of the leading countries in blueberry cultivation. In particular, the scale of cultivation has dramatically increased in south China because of its advantages of a longer growing season and high economic revenue (Yu et al., 2016). Rabbiteye blueberry has become an important economic crop in Guizhou Province (Zhang et al., 2015). However, extreme high-temperature events are becoming more frequent in south China as a result of increasing temperature and climatic variability, particularly during the flowering phenophase, thereby influencing cultivation (Yang et al., 2015b). In southeast Guizhou province, the daytime ground temperatures can remain at $35^{\circ} \mathrm{C}$ for more than $4 \mathrm{~h}$ on a typical spring day, and the difference in 
temperature can exceed $30{ }^{\circ} \mathrm{C}$ within $3 \mathrm{~h}$ (Yang et al., 2017). Abnormal temperature changes occurred frequently during the 2014 to 2018 period and were associated with erratic fruit set in blueberry. Production practice in recent years has shown that temperature stress constitutes the biggest obstacle to flowering and fruit setting in rabbiteye blueberry in south China.

In flowering plants, environmental factors play an important role in the regulation of plant growth and development, and the reproductive phase is typically highly sensitive to temperature stress (Gao et al., 2014; Ohnishi et al., 2010; Saini et al., 2017; Yang et al., 2015a). Complications can include abnormal meiosis (Bita et al., 2011; Draeger and Moore, 2017; Ohnishi et al., 2010; Yang et al., 2015a); accelerated pollen development and increased pollen abortion (Higuchi et al., 1998; Shen et al., 1999); accelerated flower bud development, resulting in a hastening of flowering time (Rodrigo and Herrero, 2002); reduced pollen germination for underdeveloped pistils (Hedhly et al., 2004; Koubouris et al., 2009; Pham et al., 2015); faster pollen tube growth in the style (Hedhly et al., 2004; $\mathrm{Xu}$ and $\mathrm{Xu}$, 2014); inhibition of pollen tube elongation (Zhang et al., 2018); reduction in the number of pollen tubes (Radičević et al., 2016); and reduction in the percentage of the style traversed by the pollen tube (Gao et al., 2014; Koubouris et al., 2009; Pham et al., 2015; Song and Chen, 2018), all of which can result in low fruit set. The aforementioned phenotypic characteristics are closely related with the genotypes of the species and botanical varieties (Pham et al., 2015; Radičević et al., 2016; Sorkheh et al., 2011).

However, a limited number of studies have attempted to clarify the effects of temperature on pollination and fertilization in blueberry. Nesmith et al. (1999) found that the corollas were most sensitive to freeze damage, followed by the styles and then the ovaries. Pollen viability was extremely low or lacking following $3 \mathrm{~d}$ or more of rain, and the stigma was unreceptive under drip film irrigation (Yang et al., 2015b). In addition, pollen viability and stigma receptivity were significantly reduced with increases or decreases in optimum temperature (Yang et al., 2017). To date, no studies have determined whether temperature reduces pollen germination in situ in blueberry, inhibits pollen tube elongation, or reduces ovule viability, which would have consequences for fertilization and fruit setting.

Using the rabbiteye blueberry 'Brightwell' as the study material, field/greenhouse-based and controlled temperature experiments were carried out over two consecutive years in the present study to assess the influence of different temperatures during pollination on pollen germination, pollen tube growth, and ovule viability. This study aims to provide a basis for clarifying the mechanism of heat suppression in rabbiteye blueberry fruit production and seeks to determine the temperature conditions for improved production and decreased damage from temperature stress. In addition, the cardinal temperatures can inform breeding strategies for blueberry tolerance to heat stress, which is of great significance for breeding heat-tolerant germplasms.

\section{Materials and Methods}

Plant material. The experiments were carried out over two consecutive years, 2016 and 2017, on different trees from a 5year-old orchard of 'Brightwell', which is particularly prone to erratic fruit set. The experiments were conducted at the experimental orchard of the Practice and Training Center for Horticulture, Kaili University, Kaili, Guizhou, China (lat. $26^{\circ} 31^{\prime} \mathrm{N}$, long. $\left.107^{\circ} 53^{\prime} \mathrm{E}\right)$. The orchard is situated in a tropical/subtropical climate at an altitude of $689 \mathrm{~m}$ and experiences an average annual temperature of $16.2{ }^{\circ} \mathrm{C}$, an average maximum temperature of 25 to $27^{\circ} \mathrm{C}$ (July), an average minimum temperature of 4 to $7^{\circ} \mathrm{C}$ (December), average annual sunshine of around of $1290 \mathrm{~h}$, average annual rainfall of $1240 \mathrm{~mm}$, and at least 280 frost-free days in a year. The orchard was cultivated on the open ground with a plant spacing of $2 \mathrm{~m}$ and row spacing of $2.5 \mathrm{~m}$ and was irrigated with a drip irrigation system with underground water with a hardness of $325 \mathrm{mg} \cdot \mathrm{L}^{-1}$ (as $\mathrm{CaCO}_{3}$ ) and $\mathrm{pH}$ of 7.28. The soil in the orchard was weakly acidic with a $\mathrm{pH}$ value of 5.68, the effective contents of $\mathrm{N}, \mathrm{P}$, and $\mathrm{K}$ were $145.80,10.96$, and $34.53 \mathrm{mg} \cdot \mathrm{kg}^{-1}$, respectively, and the organic matter content was $39.40 \mathrm{~g} \cdot \mathrm{kg}^{-1}$. The 'Gardenblue' variety was used as the male parent in the same orchard, and the pollen was collected in a $2-\mathrm{mL}$ centrifuge tube from directly under the corolla mouth by tapping the corolla with forceps on the day of pollination.

FIELD-BASED AND GREENHOUSE TEMPERATURE TREATMENTS. We aimed to elucidate whether the unstable fruit set was due to temperature changes. A total of 90 5-year-old blueberry trees exhibiting robust and consistent growth were randomly selected for the experimental temperature treatments, 45 of which were cultured in a greenhouse, whereas the other 45 were cultured in the field. The trees were managed according to local field practices. To maintain a soil $\mathrm{pH}$ suitable for blueberry growth requirements, the soil was irrigated with wood vinegar solution ( $\mathrm{pH} 4.32$ ) once every $20 \mathrm{~d}$. Based on the methods of Hedhly et al. (2004) and Rodrigo and Herrero (2002), at the balloon stage, the temperatures inside and outside the greenhouse were monitored every $5 \mathrm{~min}$ with a temperature logger (ZDR-20; Hangzhou Zida Instrument Co., Hangzhou, China) placed at $60 \mathrm{~cm}$ above the soil level and orientated to the north during the experimental period.

At the beginning of the flowering phenophase, bushes with sufficient flowering capacity and with flowers exhibiting uniform growth were selected from the open field and the greenhouse. From 5 to 13 Mar. 2016, 360 flowers at the balloon stage from the greenhouse plants and 360 flowers at the balloon stage from the field-grown plants were emasculated and bagged to avoid selfing and open pollination, respectively. Before this, the early or late flowers were thinned daily. On the second day after emasculation, from 1030 to $1200 \mathrm{HR}$, pollination was facilitated by sweeping a small brush containing the pollen from 'Gardenblue' onto the stigma until the pollen was visible, and the pollinated flowers were isolated again with the bags, following pollination. Sixty pollinated flowers were then sampled from the inside or outside treatments at $120 \mathrm{~h}$ after pollination, and 20 flowers each from outside and inside the greenhouse were measured using the method described in the fixation and microscopic observation section, with three replications. The remaining flowers of the two treatments were used for calculating the fruit set at $30 \mathrm{~d}$ after pollination using 100 flowers each from outside and inside the greenhouse, and three replications were tested. Furthermore, to elucidate whether the erratic fruit set was due to a lack of pollinators, from 7 to 15 Mar. 2016, 300 flowers from the outside treatment at the balloon stage were marked daily and used to calculate the fruit set of the openpollinated flowers as a control analysis. 
CONTROlled TEMPERATURE EXPERIMENTS. The controlled temperature experiments were carried out in 2017. In the fullbloom stage, to evaluate pollen germination, pollen tube growth, and ovule longevity under unfavorable temperatures during pollination and fertilization, branches containing inflorescences were placed in a controlled climate chamber at a humidity of $80 \%$. Their stem bases were immersed in $1 \%(\mathrm{w} / \mathrm{v})$ sucrose, and they were subjected to $0,5,10,15,20,25,30$, or $35{ }^{\circ} \mathrm{C}$ treatments, which covers the typical temperature range during the flowering phenophase. The nutrient solution was changed daily. Before the controlled temperature treatments, the early or late flowers were thinned, and the balloon-stage flowers were emasculated. After $24 \mathrm{~h}$ of cultivation at a constant temperature, 540 flowers in each temperature treatment at the balloon stage were pollinated as described in the field experiment temperature treatment. Sixty pollinated flowers from each temperature treatment were sampled at 2 , $4,8,12,24,48,72,96$, and $120 \mathrm{~h}$ after pollination, and 20 flowers from each sampled treatment were measured by the method described in the fixation and microscopic observation section, with three replications.

To determine the critical temperature and duration of tolerance, branches containing inflorescences were cultured in a controlled climate chamber at $0,5,10,15,20,25,30$, or $35^{\circ} \mathrm{C}$ as described in the previous paragraph. Before the treatments, the early or late flowers were thinned, and the balloon-stage flowers were emasculated and pollinated as described in the aforementioned methods. In contrast to the previous section, 60 flowers from each temperature treatment were pollinated after $4,8,12,24,48,72,96$, and $120 \mathrm{~h}$ of constant temperature after cultivation or before the style became brown and withered. In addition, to elucidate the resistance of the ovule to temperature, an additional 60 emasculated flowers were collected after 4, 8, $12,24,48,72,96$, and $120 \mathrm{~h}$ of cultivation at different constant temperatures before pollination, and 20 flowers from each collected treatment were measured by the method described in the fixation and microscopic observation section, with three replications.

FiXATION AND MICROSCOPIC OBSERVATION. In all treatments, the styles and ovaries were fixed immediately after sampling in FAA solution [5:5:90 (v/v/v) 38\% formaldehyde: acetic acid: $70 \%(\mathrm{v} / \mathrm{v})$ ethanol] and softened for fluorescence microscopy, as described by Yang et al. (2012). The pistils and ovaries were then washed in distilled water (three times, $2 \mathrm{~h}$ each), softened until they became transparent by immersion in $1 \mathrm{~mol} \cdot \mathrm{L}^{-1} \mathrm{NaOH}$ $\left(25^{\circ} \mathrm{C}\right)$, and stained in $0.1 \%$ aniline blue $\left(0.1 \% \mathrm{~K}_{3} \mathrm{PO}_{4}\right)$ for $48 \mathrm{~h}$ successively. Based on the method of Yang et al. (2012), the pollen germination performance at the stigma and the pollen tube performance at the style and the ovary were measured in compressed preparations with a fluorescence microscope (Olympus, Tokyo, Japan) equipped with a generic description filter (U-MWU; Olympus). Images were captured with a generic description camera (Olympus).

Evaluation OF THE EFFECTS OF TEMPERATURE ON POLLEN PERformance AND POLlen tUbe GROWTH. Pollen performance, expressed as pollen germination and pollen tube growth, was studied in all temperature treatments. The pollen was identified as germinating based on the pollen tube length being at least equal to or greater than the pollen grain diameter (Acar and Kakani, 2010), and the effects of temperature on pollen germination were evaluated based on the pollen germination rate and germination tendency. The effects of temperature on pollen tube growth were determined based on the percentage of the style traversed by the pollen tube (upper third of the style, half of the style, and the base of the style and ovary) under various temperature conditions (Hedhly et al., 2004; Yang et al., 2015c). Ovule longevity was determined according to the method described by Rosellini et al. (2003); specifically, an ovule was considered to be degenerative when it had a callose layer at the chalazal end (Rodrigo and Herrero, 2002; Rosellini et al., 2003). The number of ovules with a callose layer at the chalazal end was recorded.

DAta ANALYsis. All statistical analyses were performed in SPSS (version 16.0; IBM Corp., Armonk, NY). Percentages were subjected to angular transformation to ensure normality before analysis of variance at $P \leq 0.05$, followed by StudentNewman-Keuls multiple range tests. In addition, the maximum pollen germination rate, percentages of the ovules reached by the pollen tubes, and ovules with callose deposition recorded were analyzed by the quadratic and modified bilinear equations commonly used to quantify developmental responses to temperatures (Acar and Kakani, 2010). Based on the methods of the quadratic model described by Acar and Kakani (2010), the critical temperatures [minimum $\left(T_{\min }\right)$, optimum $\left(T_{\text {opt }}\right)$, and maximum $\left.\left(T_{\max }\right)\right]$ of pollen germination, pollen tube growth, and ovule longevity were estimated using the following equations:

$$
\begin{gathered}
y=a+b T-c T^{2}, \\
T_{\mathrm{opt}}=\frac{-b}{2 c}, \\
T_{\min }=\frac{-b+\sqrt{b^{2}-4 a c}}{2 c}, \\
T_{\max }=\frac{-b-\sqrt{b^{2}-4 a c}}{2 c} .
\end{gathered}
$$

In the equations, $T$ is the actual treatment temperature, and $a$, $b$, and $c$ are constants generated using PROC NLIN in SPSS.

\section{Results}

TeMPERATURE DIFFERENCES BETWEEN OUTSIDE AND INSIDE THE GREENHOUSE. The minimum, maximum, and daily mean temperatures outside and inside the greenhouse from 7 to 20 Mar. 2016 are indicated in Table 1 . The greenhouse induced a mean increase in the minimum temperature of 4.1 to $5.9^{\circ} \mathrm{C}$, maximum temperature of 4.4 to $6.4^{\circ} \mathrm{C}$, and daily mean temperature of 4.8 to $5.5^{\circ} \mathrm{C}$. During the pollination experiment, the lowest temperature outside the greenhouse was $1.2^{\circ} \mathrm{C}$, whereas the lowest temperature inside the greenhouse was $6.3{ }^{\circ} \mathrm{C}$. The highest temperature outside the greenhouse was $28.4{ }^{\circ} \mathrm{C}$, whereas the highest temperature inside the greenhouse was $33.6^{\circ} \mathrm{C}$. Furthermore, on 7 Mar., the maximum temperature reached $25^{\circ} \mathrm{C}$ outside the greenhouse, whereas the maximum temperature reached $31.4{ }^{\circ} \mathrm{C}$ inside the greenhouse, where it was maintained in an excess of $3.5 \mathrm{~h}$. The temperature outside the greenhouse dropped to $19.7^{\circ} \mathrm{C}$ within $3 \mathrm{~h}$ on $8 \mathrm{Mar}$. The minimum temperature was $1.2^{\circ} \mathrm{C}$ on 10 Mar., whereas the daily mean temperature was $2.4^{\circ} \mathrm{C}$.

Pollen tube Growth AND FRUIT SET DIFFERENCES BetWeEN OUTSIDE AND INSIDE THE GREENHOUSE. During the pollination test, the average temperature from pollination to sampling 


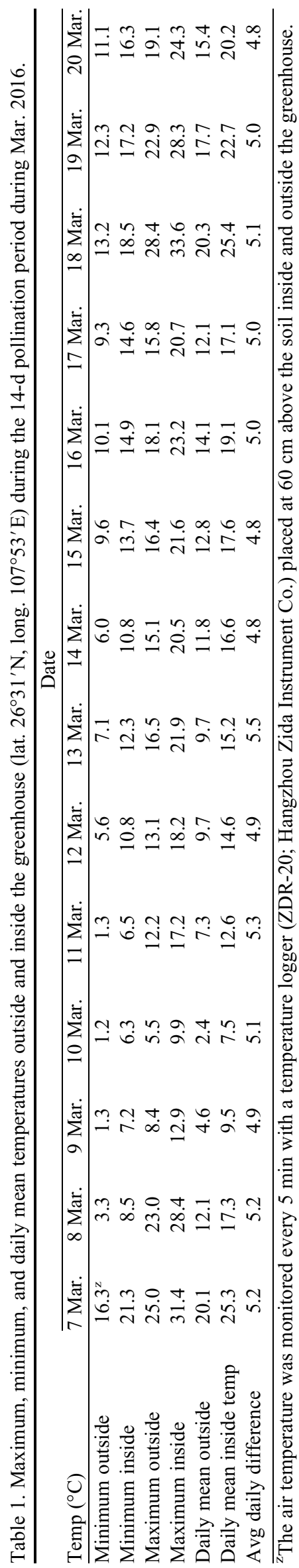

exhibited a consistent daily trend inside and outside the greenhouse, with lower temperatures being recorded during the beginning of the treatment and increasing toward the end of the treatment (Table 2). The lowest average temperatures were 7.6 and $12.7{ }^{\circ} \mathrm{C}$, respectively, recorded on 8 and 9 Mar., whereas the highest average temperatures were 15.4 and $20.4{ }^{\circ} \mathrm{C}$, respectively, recorded on 15 Mar. Outside the greenhouse, the average temperature from pollination to sampling did not exceed $9.5^{\circ} \mathrm{C}$ from 7 to 10 Mar., and the pollen tube failed to grow through the style and into the embryo sac. By contrast, the average temperatures of the corresponding treatment inside the greenhouse ranged from 12.7 to $14.5^{\circ} \mathrm{C}$, $23.3 \%$ to $58.3 \%$ of the style was traversed by the pollen tube, and $37.8 \%$ to $41.1 \%$ of the ovules were reached by the pollen tube.

During the pollination test, the effect of temperature on the percentage of the style and ovules that were traversed by the pollen tube was assessed. Outside the greenhouse, the highest percentages of the style traversed by the pollen tube and the percentage of the ovules traversed by the pollen tube were $81.7 \%$ and $44.4 \%$, respectively, on 15 Mar. Inside the greenhouse, the highest percentages of the style and ovules traversed by the pollen tube were $91.7 \%$ and $54.4 \%$ on 11 to 12 and 13 Mar., respectively. These values dropped significantly to $78.8 \%$ and $48.9 \%$, respectively, when the average temperature increased to $20.4{ }^{\circ} \mathrm{C}$ on 15 Mar.

The fruit set during artificial pollination inside the greenhouse was significantly higher than that outside the greenhouse. The fruit set outside the greenhouse ranged only from $5.0 \%$ to $12.7 \%$ on 7 to 11 Mar., and the lowest fruit set of $5.0 \%$ was recorded on 9 Mar., whereas the highest $(53.7 \%)$ was recorded on 15 Mar. By contrast, the fruit set inside the greenhouse ranged from $43.0 \%$ to $52.3 \%$ from 7 to 11 Mar., with the lowest value of $43.0 \%$ recorded on 9 Mar. and the highest value of $75.0 \%$ recorded on 13 Mar. The fruit sets of the artificially pollinated and open-pollinated plants differed. Both treatments were low from 7 to 11 Mar. and differed significantly from each other from 7 to 9 Mar. The fruit sets of both treatments increased significantly from 12 to 15 Mar., but did not differ significantly from one another. Both were significantly lower than the fruit set of the artificially pollinated plants inside the greenhouse.

EFFECTS OF TEMPERATURE ON POLLEN GERMinAtion. Pollen germination gradually accelerated with the increase in temperature, but the percentage of the style traversed by the pollen tube did not increase gradually with the increase in temperature (Table 3 ). The pollen did not germinate until $120 \mathrm{~h}$ after pollination at $0{ }^{\circ} \mathrm{C}$, and very little germinated pollen was observed until $96 \mathrm{~h}$ after pollination at $5{ }^{\circ} \mathrm{C}$. Germinated pollen was observed at $2 \mathrm{~h}$ after pollination from 15 to $35^{\circ} \mathrm{C}$, but was only observed at $4 \mathrm{~h}$ after pollination at $10{ }^{\circ} \mathrm{C}$. The percentage of the style with germinated pollen peaked at $24 \mathrm{~h}$ or $48 \mathrm{~h}$ after pollination.

In addition, comparative analysis indicated that the percentage of the style with germinated pollen was higher than $90 \%$ at 20.0 or $25.0{ }^{\circ} \mathrm{C}$, which was significantly higher than the percentage of the style with germinated pollen at 10, 15, 30, and $35{ }^{\circ} \mathrm{C}$. In particular, the percentage of the style with germinating pollen was lower by $\approx 56 \%$ in the 10,15 , and $30^{\circ} \mathrm{C}$ treatments, whereas the pollen did not germinate at $35^{\circ} \mathrm{C}$. Only a few styles had germinating pollen at $5{ }^{\circ} \mathrm{C}$. Based on the quadratic equation $Y=-7.292+9.455 T-0.221 T^{2}\left(r^{2}=0.931\right)$ 


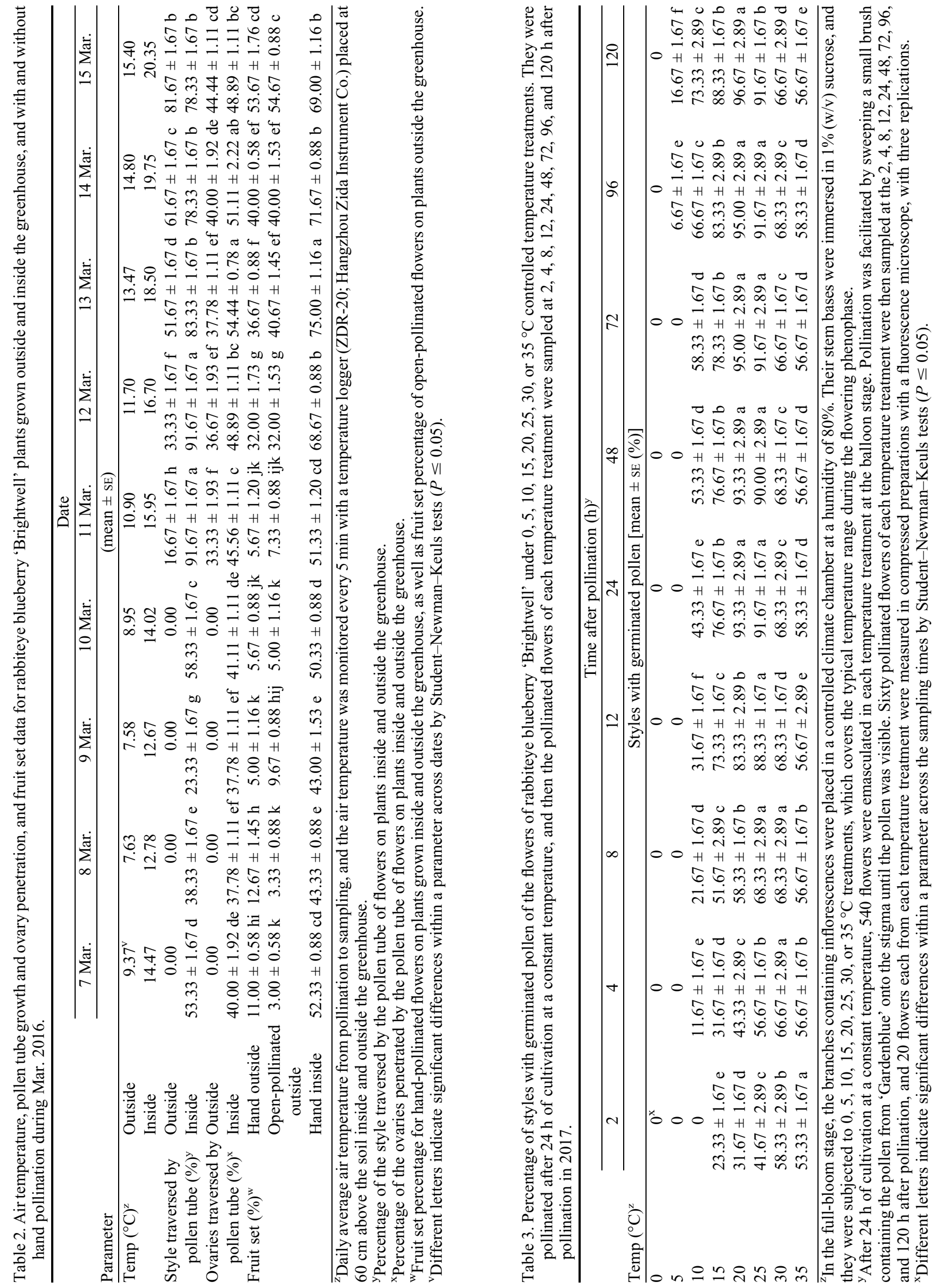


by linear regression analysis, the predicted $T_{\min }, T_{\mathrm{opt}}$, and $T_{\max }$ of pollen germination of 'Gardenblue' in 'Brightwell' pistils were $0.8,21.4$, and $42.0^{\circ} \mathrm{C}$, respectively.

EFFECTS OF TEMPERATURE ON POLLEN TUBE GROWTH. Pollen tube growth increased with increasing temperature within a certain temperature range (Table 4). No pollen germinated at $0{ }^{\circ} \mathrm{C}$, and pollen tube growth was extremely slow at $5.0^{\circ} \mathrm{C}$, with the pollen tube only reaching the upper third of the style at $120 \mathrm{~h}$ after pollination (Table 4). At $10{ }^{\circ} \mathrm{C}$, only $8.3 \%$ of the upper third of the style had been traversed by the pollen tube at $12 \mathrm{~h}$ after pollination (Table 4 ), whereas $11.7 \%$ of the upper half of the style had been traversed at $72 \mathrm{~h}$ after pollination (Table 5). At temperatures of $15,20,25$, and $30^{\circ} \mathrm{C}$, the time required for the pollen tube to reach the upper third of the style, the upper half of the style, and the base of the style was correspondingly reduced. The style was traversed by the pollen tube at $48 \mathrm{~h}$ after pollination at these temperatures (Table 6).

At $120 \mathrm{~h}$ after pollination, the percentage of the style traversed by the pollen tube at 15 and $20^{\circ} \mathrm{C}$ was significantly higher than at $25^{\circ} \mathrm{C}$ and was significantly higher at $25^{\circ} \mathrm{C}$ than at 10.0 and $30^{\circ} \mathrm{C}$. Based on the quadratic equation of $Y=-8.519+$ $5.420 T-0.147 T^{2}\left(r^{2}=0.882\right)$, the $T_{\min }, T_{\mathrm{opt}}$, and $T_{\max }$ of the pollen tube growth of 'Gardenblue' in 'Brightwell' pistils were predicted to be $1.6,18.4$, and $35.2^{\circ} \mathrm{C}$, respectively.

The pollen tubes required at least $96 \mathrm{~h}$ of growth to reach the ovules at $10,15,20,25$, and $30{ }^{\circ} \mathrm{C}$ (Table 7). However, there was a significant difference in the pollen tube growth percentage between the different temperature treatments. At 15 and $20{ }^{\circ} \mathrm{C}$, the pollen tubes had reached $40 \%$ of the ovules, whereas at 25 and $10{ }^{\circ} \mathrm{C}$, the corresponding percentages were $36 \%$ $\approx 33 \%$, respectively, and at $30{ }^{\circ} \mathrm{C}$, this value was only $\approx 22 \%$. The pollen tube did not reach the ovules in the 0,5 , and $35^{\circ} \mathrm{C}$ treatments. The aforementioned results showed that temperatures of 15 and $20{ }^{\circ} \mathrm{C}$ were associated with improved pollen tube growth, whereas temperatures below or above these values were associated with reduced pollen tube growth.

EFFECTS OF CULTIVATION DURATION AND TEMPERATURE ON POLLEN GERMINATION. To elucidate the critical temperature and duration of tolerance, cut flowers were cultured in a controlled climate chamber at $0,5,10,15,20,25,30$, or $35^{\circ} \mathrm{C}$ and pollinated after $4,8,12,24,48,72,96$, and $120 \mathrm{~h}$ of controlled temperature culture (Table 8). No pollen germination occurred at $0{ }^{\circ} \mathrm{C}$, and at $5{ }^{\circ} \mathrm{C}$, only $16.7 \%$ or $18.3 \%$ of the style contained germinated pollen at $4,8,12$, and $24 \mathrm{~h}$ after cultivation, and there was no significant difference between the time treatments (Table 8). However, at temperatures of 10, 15, 20, 25, 30, and $35^{\circ} \mathrm{C}$, there were significant differences between the different temperatures or treatment durations after cultivation under the same temperature.

Generally, the percentage of the style with germinated pollen increased initially with time but then decreased, with the maximum percentage of the style with germinating pollen appearing earlier under all the temperature treatments. The maximum percentage of the style with germinated pollen was $73.3 \%$ and $93.3 \%$ after $48 \mathrm{~h}$ of cultivation at 10 and $15{ }^{\circ} \mathrm{C}$, respectively, and $93.3 \%$ after $24 \mathrm{~h}$ cultivation at 20 and $25^{\circ} \mathrm{C}$. By contrast, at 30 and $35{ }^{\circ} \mathrm{C}$, these values were $66.7 \%$ and $61.7 \%$, respectively, after $48 \mathrm{~h}$ of cultivation. After $72 \mathrm{~h}$ of cultivation, the style had become brown and withered in all treatments and could not be pollinated.

EFFECTS OF CULTIVATION DURATION AND TEMPERATURE ON POLLEN TUBE GROWTH. There were significant differences in the

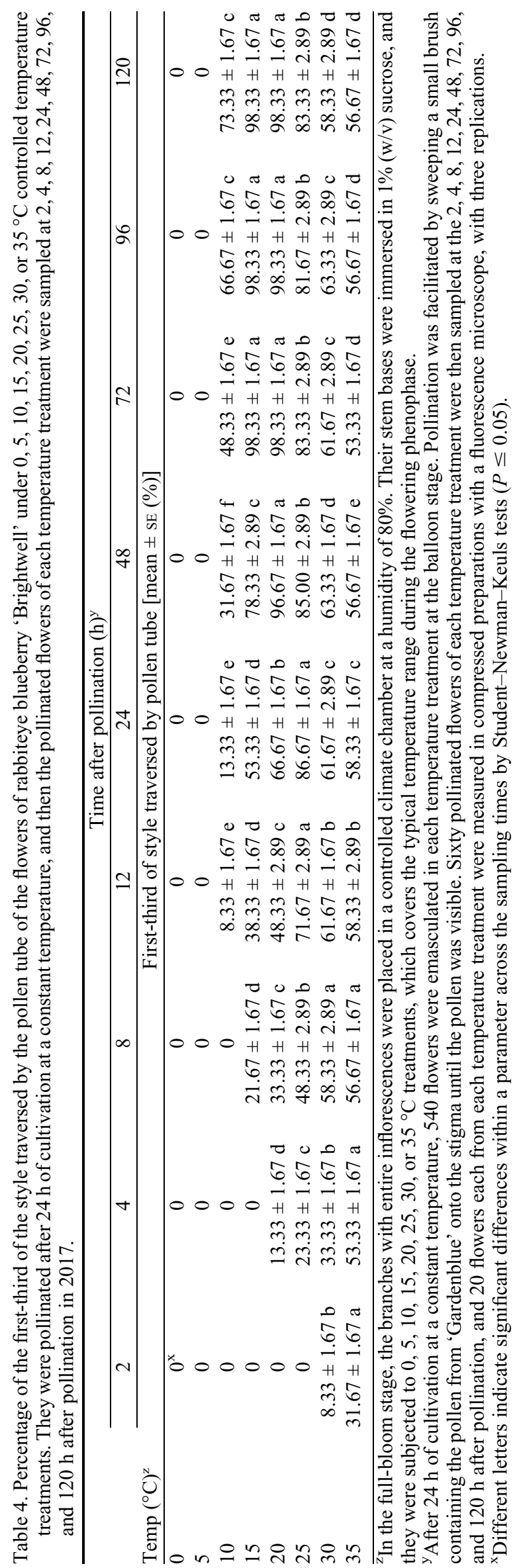

J. Amer. Soc. Hort. ScI. 144(5):339-351. 2019. 

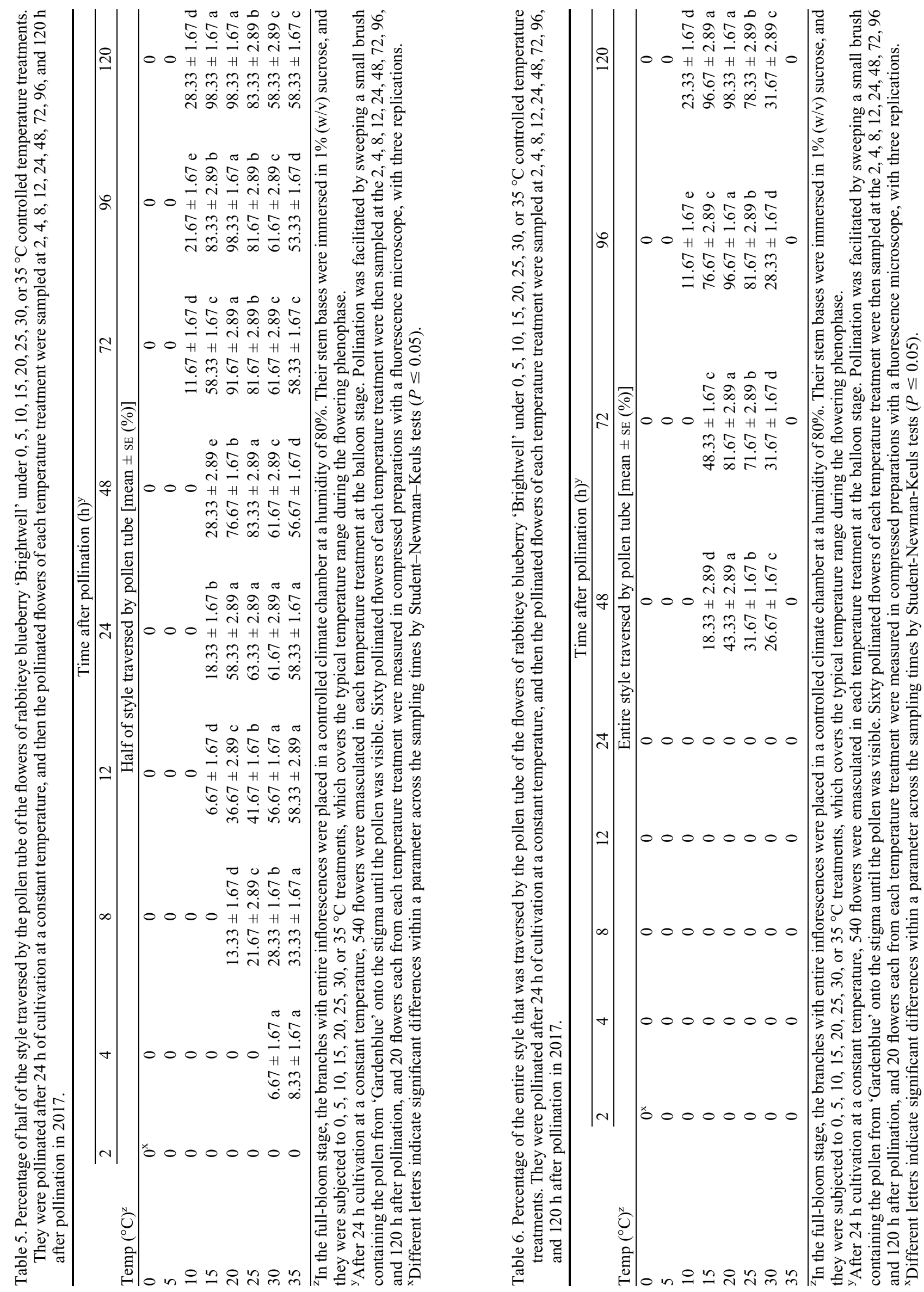

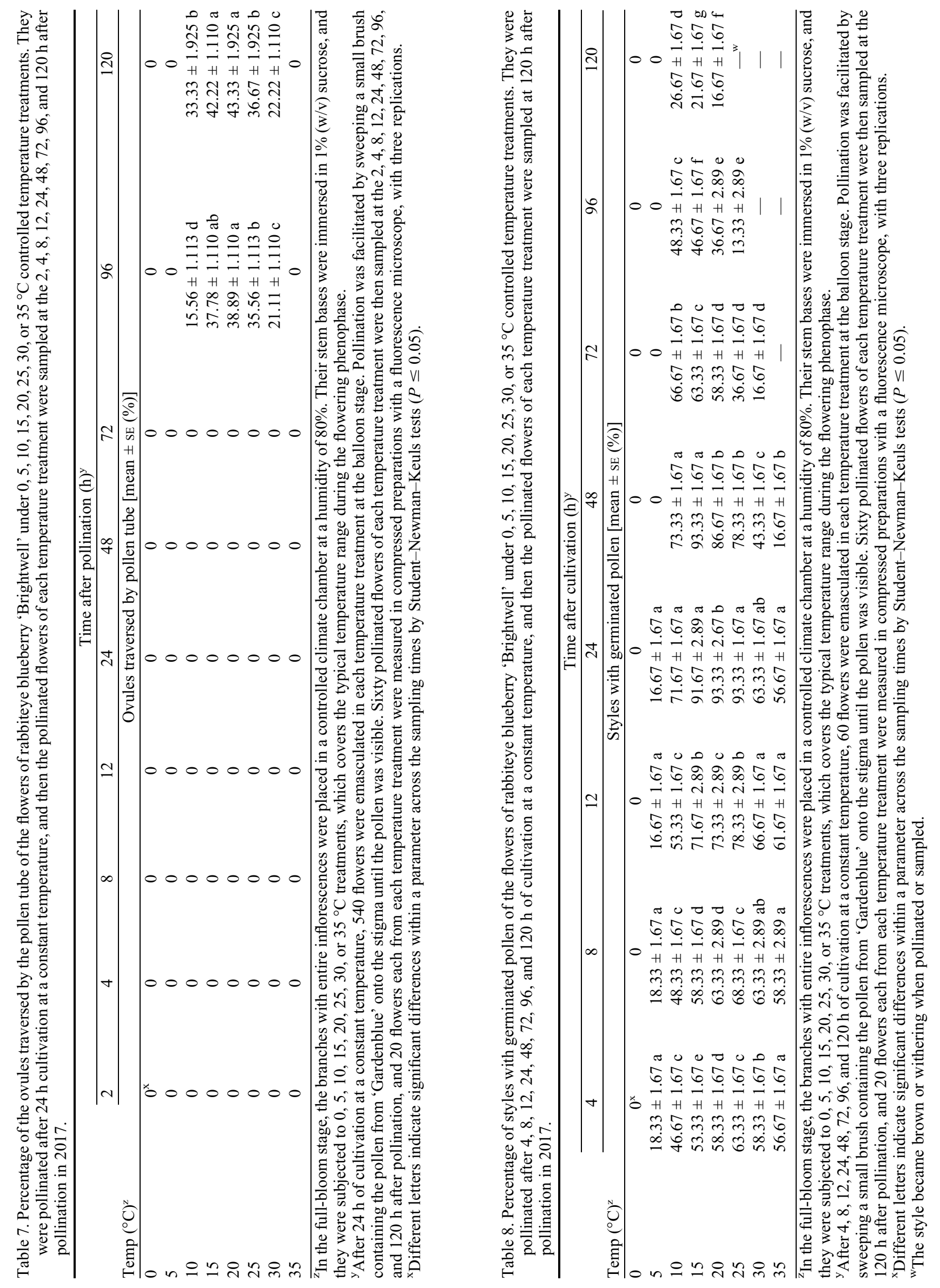
percentage of the style (upper third of the style, upper half of the style, and the whole style) that was traversed by the pollen tube among the different cultivation durations, with the exception of the $0{ }^{\circ} \mathrm{C}$ treatment, where no pollen tube growth was observed (Tables 9-12). At temperatures of $10,15,20$, and $25^{\circ} \mathrm{C}$, the percentage of the style traversed by the pollen tube had begun declining following pollination and cultivation for more than 48 h. At 10,15 , and $20^{\circ} \mathrm{C}$, the pollen tube had not reached the upper half of the style, but had traversed the upper third of the style at $120 \mathrm{~h}$ following pollination. At all treatment temperatures, the pollen tube did not traverse the entire style at $96 \mathrm{~h}$ following pollination. Notably, at $35{ }^{\circ} \mathrm{C}$, the percentage of the style traversed by the pollen tube was only $3.3 \%$ and $1.7 \%$ at 4 and $8 \mathrm{~h}$ after pollination, respectively, and the pollen tube did not reach the ovules.

EFFEcts OF CULTIVATION DURATION UNDER CONSTANT TEMPERATURE ON OVULE LONGEVITY. The results of the effect of temperature on ovule degeneration indicated that the percentage of ovule degeneration accelerated with increasing temperature after $120 \mathrm{~h}$ of cultivation (Table 13). It is worth noting that the percentage of the ovule with callose deposition was increased significantly after only $4 \mathrm{~h}$ culture at 30 and $35^{\circ} \mathrm{C}$, and the percentage of degenerated ovules was $\approx 74 \%$ and $100 \%$, respectively, at $120 \mathrm{~h}$ culture, which was significantly higher than the percentage of degenerated ovules under other temperature conditions. However, at 0 and $5{ }^{\circ} \mathrm{C}$, the percentage of degenerated ovules differed slightly between the different cultivation durations, and the percentage of degenerated ovules was $\approx 35 \%$ after $120 \mathrm{~h}$ cultivation, which was significantly lower than the percentage of degenerated ovules at $25^{\circ} \mathrm{C}$. At $10,15,20$, and $25^{\circ} \mathrm{C}$, the ovule degeneration percentages were $\approx 40 \%, 43 \%, 44 \%$, and $63 \%$, respectively, indicating that higher temperatures accelerated ovule degeneration in blueberry.

\section{Discussion}

Temperature is among the most important climatic factors affecting plant reproductive processes such as pollen germination, pollen tube growth, and fruit setting (Acar and Kakani, 2010), and its consequences on reproductive success may increase with global warming (Hedhly et al., 2004). The effects of temperature on pollen germination in different species or different botanical varieties in the same species are diverse, as has been found in almond [Prunus sp. (Sorkheh et al., 2011)], apple [Malus domestica (Xu and Xu, 2014)], longan [Dimocarpus longan (Pham et al., 2015)], loquat [Eriobotrya japonica (Yang et al., 2015c)], mango [Mangifera indica (Sukhvibul et al., 2000)], and sweet cherry [Prunus avium (Radičević et al., 2016)]. The optimal temperature range for pollen germination in the aforementioned species was often close to the average temperature of their flowering phenophase. The results of this study corroborate these previous studies, with significantly higher pollen germination percentages recorded under average temperatures of 15,20 , and $25{ }^{\circ} \mathrm{C}$ during the flowering phenophase, and the predicted $T_{\min }, T_{\mathrm{opt}}$, and $T_{\max }$ of pollen germination of 'Gardenblue' in 'Brightwell' pistils were 0.8 , 21.4 , and $42.0^{\circ} \mathrm{C}$, respectively. This might be because higher or lower temperatures inhibit stigmatic mucus secretion, which reduces pollen germination as a result of the altered physiological conditions (Hedhly et al., 2003). In addition, research on the influence of temperature on pollen tube growth in pear

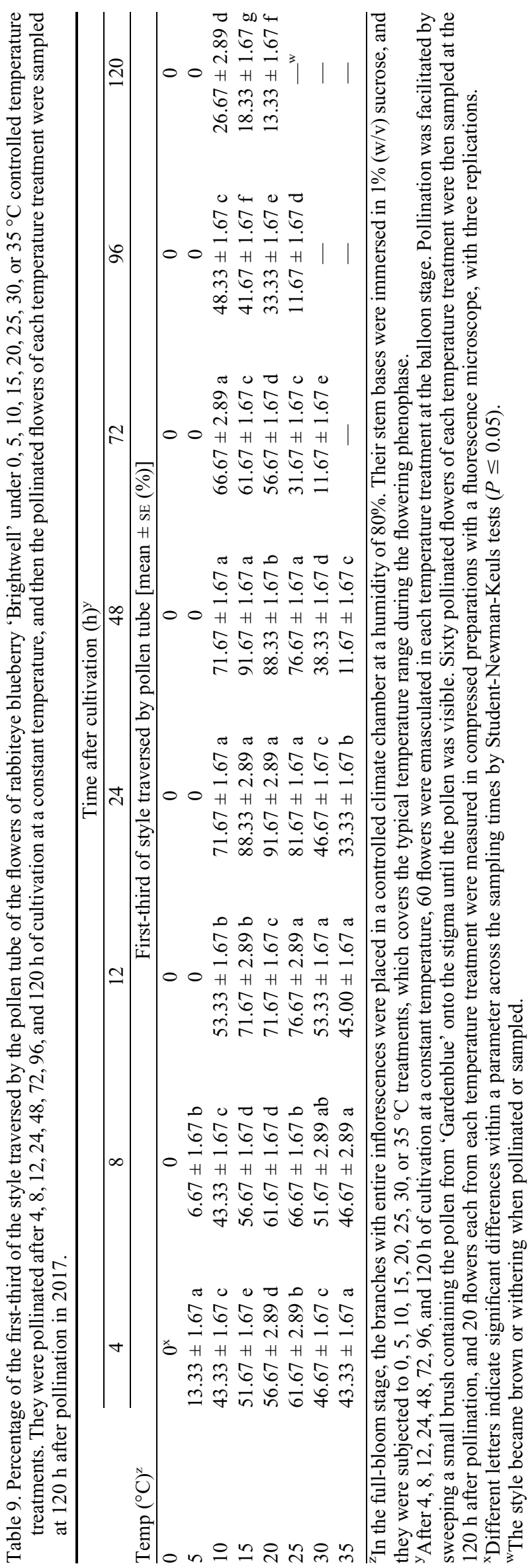




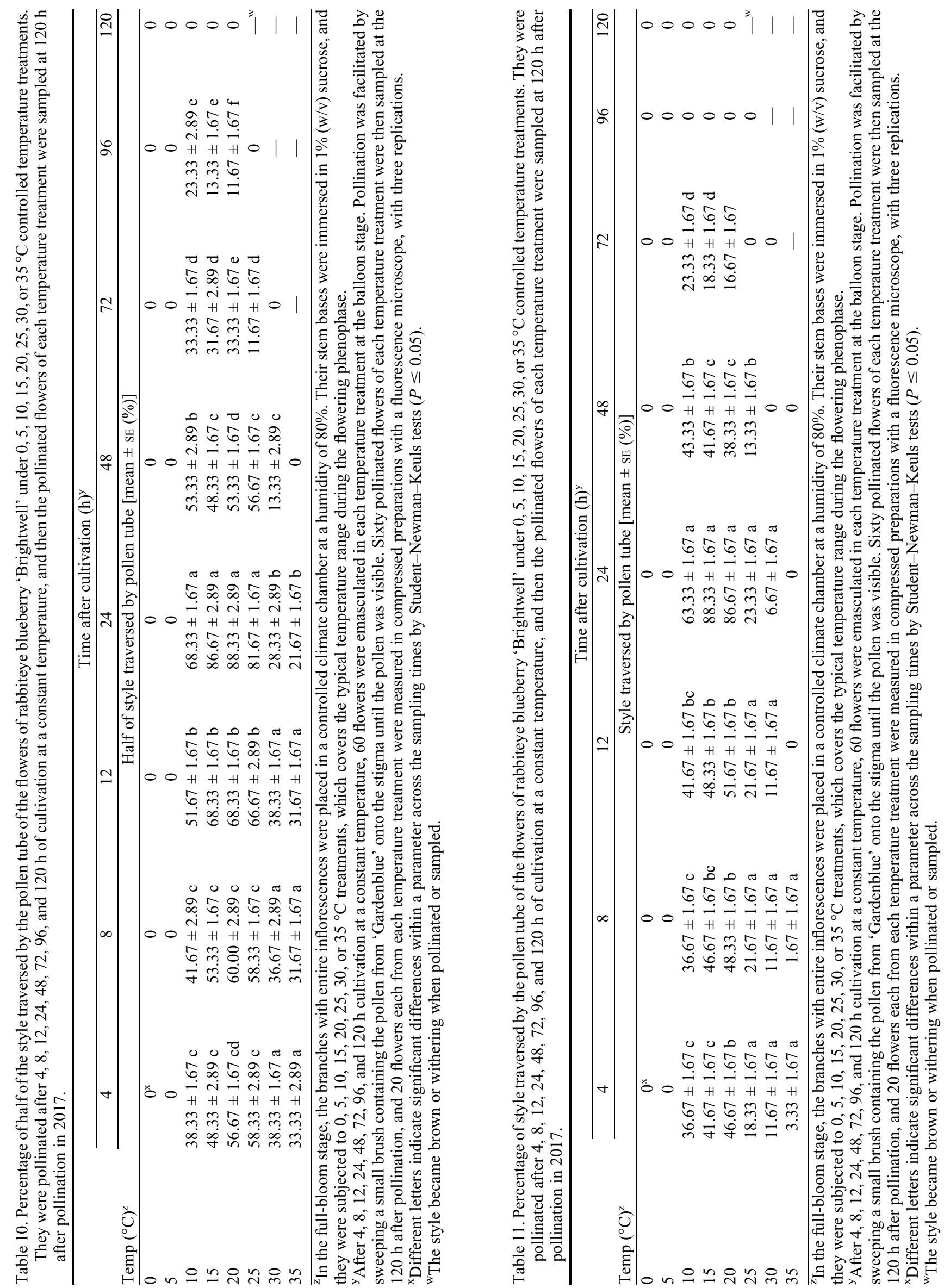



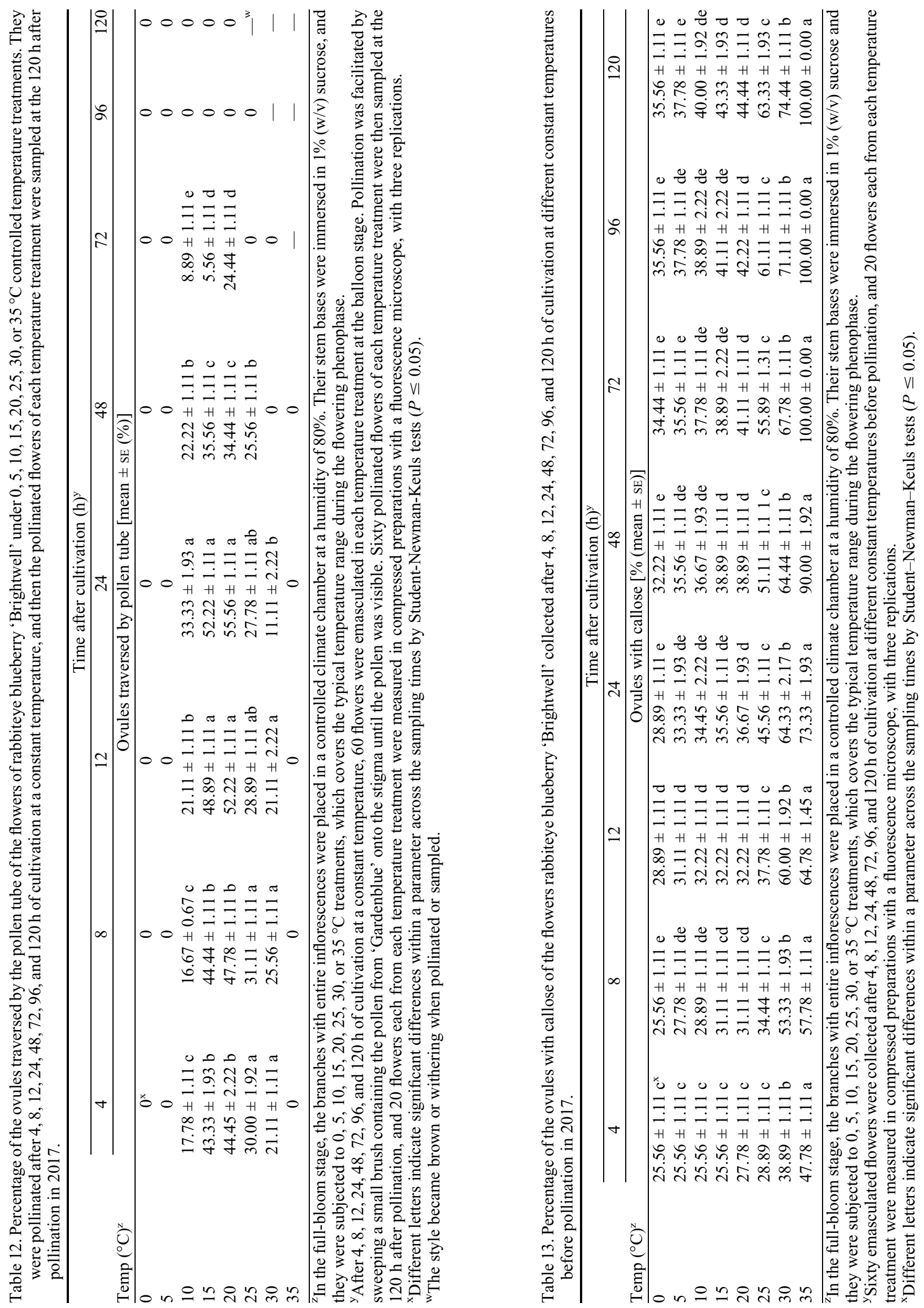
[Pyrus sp. (Vasilakakis and Porlingis, 1985)], sour cherry [Prunus cerasus (Cerović and Ružić, 1992)], apricot [Prunus armeniaca (Austin et al., 1998)], and apple (Petropoullou and Alston, 1998) indicates that pollen tube growth can be accelerated under the appropriate high-temperature range, resulting in a reduced travel time of the pollen tube to the ovules.

In this study, increased temperature could accelerate pollen tube growth in 'Brightwell' blueberry, but pollen tube growth was generally halted at the middle of the style when the temperature was $30{ }^{\circ} \mathrm{C}$, whereas no pollen tube growth was observed in the style at $35^{\circ} \mathrm{C}$. Furthermore, the percentage of the style traversed by the pollen tube at $30^{\circ} \mathrm{C}$ was significantly lower than at 15,20 , and $25^{\circ} \mathrm{C}$. These results indicated that the suitable temperature range of pollen tube growth of 15 to $25^{\circ} \mathrm{C}$ was consistent with that of pollen germination, suggesting that this temperature range during the flowering phenophase should positively influence pollination, fertilization, and fruit setting. However, it must be assumed that the ovule is still viable when the pollen tube reaches the ovule (i.e., the time required for the pollen tube to grow to the ovule is shorter than the period for which the ovule maintains its viability). More than $55 \%$ ovule viability was recorded at $96 \mathrm{~h}$ after cultivation at 15,20 , and $25^{\circ} \mathrm{C}$, which is consistent with the percentage of ovules with pollen tubes at this time.

Low temperatures and wet, cold weather are frequent in spring during the blueberry flowering phenophase and are the result of the changes in global climate in recent years, which has become a constraint on the sustainable development of blueberries in some regions (Yang et al., 2015b, 2017). In this study, the predicted $T_{\min }, T_{\mathrm{opt}}$, and $T_{\max }$ of the pollen tube growth of 'Gardenblue' in 'Brightwell' pistils were predicted to be 1.6, 18.4 , and $35.2{ }^{\circ} \mathrm{C}$, respectively, which imply that the suitable pollination and fertilization temperatures were in the range of 15 to $25^{\circ} \mathrm{C}$ in blueberry. However, at temperatures of 0 and $5{ }^{\circ} \mathrm{C}$, it is worth noting that only $\approx 35 \%$ of the ovules exhibited callose deposition, indicating that $\approx 65 \%$ of the ovules were still viable. This may be due to the ability of blueberries to adapt to low temperatures through long-term natural selection, enabling them to mitigate the effects of frequent cold weather on their pollination and fertilization. However, compared with the frequent cold weather in some regions, as the greenhouse effect intensifies, the impact of global temperature rise on the reproductive process of plants is also of concern. Some studies have shown that high temperature during the flowering phenophase adversely affects pollination and fertilization in some blueberry cultivation regions in China (Yang et al., 2015b, 2017; Yu et al., 2016). In this study, the percentage of ovules with callose was increased significantly after only $4 \mathrm{~h}$ of culture at 30 and $35^{\circ} \mathrm{C}$, and the percentage of degenerated ovules was $\approx 74 \%$ and $100 \%$, respectively, at $120 \mathrm{~h}$ culture, which suggests that high temperatures could accelerate ovule degeneration.

The findings of this study demonstrated that 'Brightwell' is sensitive to a certain range of high temperatures during the flowering phenophase. The ability of blueberry to tolerate a certain high-temperature range during the flowering phenophase should thus become a focus for the breeding of temperature-resistant blueberries and should also become an important indicator for the ecological regionalization of blueberry cultivation. Of course, the influence of temperature on the reproductive process of plants is important not only during the flowering phenophase but also during the formation and development stage of the flower buds of fruit trees, such as pear, peach (Prunus persica), and apricot. Therefore, further research on the influence of preflowering temperature on the reproductive process of blueberries is required.

\section{Conclusions}

In this article, a comprehensive analysis of the effect of temperature on pollen germination, pollen tube growth, fruit set, and ovule longevity showed that temperature significantly affects pollen germination, pollen tube growth, and ovule longevity. Furthermore, pollen tube growth was accelerated by the appropriate high temperature in the appropriate temperature range, resulting in a reduced travel time of the pollen tube to the ovule. However, the pollen tubes mostly stopped growing to the middle of the style at $30^{\circ} \mathrm{C}$, and no pollen tubes traversed the style at $35^{\circ} \mathrm{C}$. In addition, high temperature also accelerated ovule degeneration. The results of the regression analysis showed that the $T_{\mathrm{opt}}$ of pollen germination and pollen tube growth were 21.4 and $18.4{ }^{\circ} \mathrm{C}$, respectively, in blueberry. Therefore, the tolerance of blueberry to a certain high-temperature range in the flowering phenophase should inform future breeding strategies for temperature resistance and is also an important indicator of suitable environments for blueberry cultivation to mitigate potential future temperature stress.

\section{Literature Cited}

Acar, I. and V.G. Kakani. 2010. The effects of temperature on in vitro pollen germination and pollen tube growth of Pistacia spp. Scientia Hort. 125:569-572.

Austin, P.T., E.W. Hewett, D. Noiton, and J.A. Plumer. 1998. Selfincompatibility and temperature affect pollen tube growth in 'Sundrop' apricot (Prunus armeniaca L.). J. Hort. Sci. Biotechnol. 73:375-386.

Bita, C.E., S. Zenoni, W.H. Vriezen, C. Mariani, M. Pezzotti, and T. Gerats. 2011. Temperature stress differentially modulates transcription in meiotic anthers of heat-tolerant and heat-sensitive tomato plants. BMC Genomics 12:384-401.

Castagnini, J.M., N. Betoret, E. Betoret, and P. Fito. 2015. Vacuum impregnation and airdrying temperature effect on individual anthocyanins and antiradical capacity of blueberry juice included into an apple matrix. Lebensm. Wiss. Technol. 64:1289-1296.

Cerović, R. and D. Ružić. 1992. Pollen tube growth in sour cherry (Prunus cerasus L.) at different temperatures. J. Hort. Sci. 67:333340.

Chu, W.J., H.Y. Gao, S.F. Cao, X.J. Fang, H.J. Chen, and S.Y. Xiao. 2017. Composition and morphology of cuticular wax in blueberry (Vaccinium spp.) fruits. Food Chem. 219:436-442.

Draeger, T. and G. Moore. 2017. Short periods of high temperature during meiosis prevent normal meiotic progression and reduce grain number in hexaploid wheat (Triticum Aestivum L.). Theor. Appl. Genet. 130:1785-1800.

Dróżdż, P., V. Šėžienė, and K. Pyrzynska. 2018. Mineral composition of wild and cultivated blueberries. Biol. Trace Elem. Res. 181:173177.

Gao, Y.B., C.L. Wang, J.Y. Wu, H.S. Zhou, X.T. Jiang, J. Wu, and S.L. Zhang. 2014. Low temperature inhibits pollen tube growth by disruption of both tip-localized reactive oxygen species and endocytosis in Pyrus bretschneideri Rehd. Plant Physiol. Biochem. 74:255-262.

Hedhly, A., J.I. Hormaza, and M. Herrero. 2003. The effect of temperature on stigmatic receptivity in sweet cherry (Prunus avium L.). Plant Cell Environ. 26:1673-1680.

Hedhly, A., J.I. Hormaza, and M. Herrero. 2004. Effect of temperature on pollen tube kinetics and dynamics in sweet cherry, Prunus avium (Rosaceae). Amer. J. Bot. 91:558-564. 
Higuchi, H., N. Utsunomiya, and T. Sakuratani. 1998. High temperature effects on cherimoya fruit set, growth and development under greenhouse conditions. Scientia Hort. 77:23-31.

Koubouris, G.C., I.T. Metzidakis, and M.D. Vasilakakis. 2009. Impact of temperature on olive (Olea europaea L.) pollen performance in relation to relative humidity and genotype. Environ. Expt. Bot. 67:209-214.

Lin, Z., J. Fischer, and L. Wicker. 2016. Intermolecular binding of blueberry pectin-richfractions and anthocyanin. Food Chem. 194:986-993.

Miller, S., P. Alspach, J. Scalzo, and J. Meekings. 2011. Pollination of 'Hortblue Petite' blueberry: Evidence of metaxia in a new ornamental home-garden cultivar. HortScience 46:1468-1471.

Müller, J.L., W.J. Steyn, and K.I. Theron. 2013. The effect of crosspollination of southern highbush blueberries on fruit set and fruit characteristics. Acta Hort. 1007:571-578.

Nesmith, D.S., G. Krewer, and O.M. Lindstrom. 1999. Fruit set of rabbiteye blueberry (Vaccinium ashei) after subfreezing temperatures. J. Amer. Soc. Hort. Sci. 124:337-340.

Nicholson, C.C. and T.H. Ricketts. 2019. Wild pollinators improve production, uniformity, and timing of blueberry crops. Agr. Ecosyst. Environ. 272:29-37.

Nile, S.H. and S.W. Park. 2014. Edible berries: Bioactive components and their effect on human health. Nutrition 30:134-144.

Ohnishi, S., T. Miyoshi, and S. Shirai. 2010. Low temperature stress at different flower developmental stages affects pollen development, pollination, and pod set in soybean. Environ. Expt. Bot. 69:56-62.

Petropoullou, S.P. and F.H. Alston. 1998. Selecting for improved pollination at low temperature in apple. J. Hort. Sci. Biotechnol. 73:507-512.

Pham, V.T., M. Herrero, and J.I. Hormaza. 2015. Effect of temperature on pollen germination and pollen tube growth in longan (Dimocarpus longan Lour.). Scientia Hort. 197:470-475.

Radičević, S., R. Cerović, D. Nikolić, and M. Đorđevic. 2016. The effect of genotype and temperature on pollen tube growth and fertilization in sweet cherry (Prunus avium L.). Euphytica 209:121-136.

Rodrigo, J. and M. Herrero. 2002. Effects of pre-blossom temperatures on flower development and fruit set in apricot. Scientia Hort. 92:125135.

Rosellini, D., F. Ferranti, P. Barone, and F. Veronesi. 2003. Expression of female sterility in alfalfa (Medicago sativa L.). Sex. Plant Reprod. 15:271-279.

Saini, R., A.K. Singh, S. Dhanapal, T.H. Saeed, G.J. Hyde, and R. Baskar. 2017. Brief temperature stress during reproductive stages alters meiotic recombination and somatic mutation rates in the progeny of Arabidopsis. BMC Plant Biol. 17:103-113.

Shen, X., X.H. Sun, Q.C. Xie, H.Q. Liu, Y. Zhao, Y.J. Pan, C.A. Hwang, and V.C.H. Wu. 2014. Antimicrobial effect of blueberry (Vaccinium corymbosum L.) extractsagainst the growth of Listeria monocytogenes and Salmonella enteritidis. Food Control 35:159165.
Shen, Y., J. Guo, C. Liu, and K. Jia. 1999. Effect of temperature on the development of peach flower organs. Acta Hort. Sinica 26:1-6.

Song, G.Q. and Q.X. Chen. 2018. Comparative transcriptome analysis of nonchilled, chilled, and late-pink bud reveals flowering pathway genes involved in chilling-mediated flowering in blueberry. BMC Plant Biol. 18:98-110.

Sorkheh, K., B. Shiran, V. Rouhi, and M. Khodambashi. 2011. Influence of temperature on the in vitro pollen germination and pollen tube growth of various native Iranian almonds (Prunus L. spp.) species. Trees 25:809-822.

Sukhvibul, N., A.W. Whiley, V. Vithanage, M.K. Smith, V.J. Doogan, and S.E. Hetherington. 2000. Effect of temperature on pollen germination and pollen tube growth of four cultivars of mango (Mangifera indica L.). J. Hort. Sci. Biotechnol. 75:214-222.

Vasilakakis, M. and I.C. Porlingis. 1985. Effect of temperature on pollen germination, pollen tube growth, effective pollination period, and fruit set of pear. HortScience 20:733-735.

Wang, L.Y., Y.D. Li, H.Y. Sun, H.G. Liu, X.D. Tang, Q.C. Wang, and Z.D. Zhang. 2017. An efficient droplet-vitrification cryopreservation for valuable blueberry germplasm. Scientia Hort. 219:60-69.

$\mathrm{Xu}$, C.S. and A.H. Xu. 2014. Effects of high temperature on germination and growth of apple pollen in style. Plant Physiol. J. 50:51-55.

Yang, J., X.R. Chen, C.L. Zhu, X.S. Peng, X.P. He, J.R. Fu, L.J. Ouyang, J.M. Bian, L.F. Hu, X.T. Sun, J. Xu, and H.H. He. 2015a. Rna-seq reveals differentially expressed genes of rice (Oryza sativa) spikelet in response to temperature interacting with nitrogen at meiosis stage. BMC Genomics 16:959-976.

Yang, Q., L. Tang, X.Y. Li, J.J. Zhou, X. Tian, J. Zhang, Y. Yue, and X.Y. Wang. 2015b. Effect of rainy on stigma receptivity and pollen viability in blueberry. Northern Hort. 39:47-49.

Yang, Q., X.Q. Wan, D.P. Li, X.Y. Li, T.T. Zhang, and S. Peng. 2017. Effect of temperature on pollen viability and stigma receptivity in 'Premier' rabbiteye blueberry. Northern Hort. 41:39-43.

Yang, Q., Y. Fu, Y.Q. Wang, L. Tao, Q.X. Deng, J.X. Fan, and R.J. Deng. 2015c. Effects of temperature on pollen tube growth and ovule longevity in loquat (Eriobotrya japonica). J. Fruit Sci. 32:646-652.

Yang, Q., Y.Q. Wang, Y. Fu, Q.X. Deng, and L. Tao. 2012. Effects of biological factors on fruit and seed set in loquat (Eriobotrya japonica Lindl.). Afr. J. Agr. Res. 7:5303-5311.

Yu, K., K.L. Zhu, M.J. Ye, Y.P. Zhao, W.R. Chen, and W.D. Guo. 2016. Heat tolerance of highbush blueberry is related to the antioxidative enzymes and oxidative protein-repairing enzymes. Scientia Hort. 198:36-43.

Zhang, C.X., G.G. Li, T.T. Chen, B.H. Feng, W.M. Fu, J.X. Yan, M.R. Islam, Q.Y. Jin, L.X. Tao, and G.F. Fu. 2018. Heat stress induces spikelet sterility in rice at anthesis through inhibition of pollen tube elongation interfering with auxin homeostasis in pollinated pistils. Rice 11:14-25.

Zhang, S.S., Y.H. Lu, D.R. Lin, and P.P. Wang. 2015. Research on the development situation and counter measures of the blueberry industry in China. For. Econ. 5:68-71. 